http://jmscr.igmpublication.org/home/

ISSN (e)-2347-176x ISSN (p) 2455-0450

crossref DOI: https://dx.doi.org/10.18535/jmscr/v7i8.118

Journal Of Medical Science And Clinical Research

\title{
Case Study of Infiltrating Carcinoma of the Breast in Correlation with the Incidence of the Estrogen Receptor [ER], Progesteron Receptor [PR] and HER2nue Status
}

\section{Authors \\ Dr Nandini Venkatesh, Dr Ramya Jayaram, Dr Vishnukumar Venkatesan}

\section{Introduction}

Globally breast carcinoma is the leading cause of cancer related death in women worldwide. Despite the high incidence rates, in Western countries, $89 \%$ of women diagnosed with breast cancer are still alive 5 years after their diagnosis, which is due to early detection and treatment. The UK and USA have one of the highest incidence rates worldwide (together with the rest of North America and Australia/ New Zealand), making these countries a priority for breast cancer awareness. Estrogen and progesterone and HER-2 protein play a central role in regulating growth kinetics of breast tissue and are powerful predictive markers. now the immunohistochemistry testing for hormonal receptors status is mandatory in breast cancer.

In urban India breast cancer accounts for about $25 \%$ to $33 \%$ of all cancers in women. In women, incidence rates of breast cancer rise sharply with age until ages 45 to50, when the rise becomes less steep. This change in slope probably reflects the impact of hormonal change (menopause) that occurs about this time. Over $50 \%$ breast cancer patients in India present in stages 3 and 4, which will definitely impact their survival and the overall 5 year survival for breast cancer patients in India doesn't appear to be even $60 \%$ presently. A number of molecular markers have been identified in invasive breast cancers that have predictive as well as prognostic value. Well known markers include the estrogen receptor $\alpha$ (ER) and progesterone receptor (PR) which are associated with improved outcomes and respond to hormone therapy. HER-2/neu is a tyrosine kinase receptor related to the epidermal growth factor receptor family. Over expression of HER$2 /$ neu in invasive carcinoma is correlated with decreased relapse-free and overall survival, and resistance to hormonal and cytotoxic therapy. Estrogen and progesterone and HER-2 protein play a central role in regulating growth kinetics of breast tissue and are powerful predictive markers. Estrogen plays a central role in regulating growth kinetics of a variety of epithelial linings, most importantly in the breast and endometrium. Breast cancer patients whose lesions contain both Estrogen receptors (ER) and Progesterone receptors (PR) have the best possibility of remission following hormonal therapy (approximately 70\%) than the group of patients whose lesions contain either receptor alone (approximately $30 \%$ ) or very low levels of both 
receptors (approximately 10\%). It has been shown that tumors expressing ER and PR tend to be better differentiated and low grade tumors. ER negative status has been shown to be predictive of recurrence of low stage tumors, independent of tumor grade, while negative PR status is associated with a significant risk of lymph node metastasis independent of other clinicopathological factors.

Breast cancer patients that have HER2/ neu gene amplification, results in glycoprotein over expression. Approximately 5\% of patients have over expression without gene amplification, but otherwise gene amplification and expression are highly correlated. HER2 amplification or over expression has been associated with higher tumor grade, lack of ER receptors, higher levels of tumor proliferation, and poorer prognosis.

\section{Materials \& Method}

This was a prospective study done from June 2018 to June 2019. 50 patients were included in this study who were admitted in our institution. The following clinical and pathological factors were correlated with ER/PR and HER 2nue status.

A) Menopausal status

B) Tumor size

C) Pathological type

D) Histological grading

E) Lymphovascular invasion

F) Nodal status

\section{Inclusion Criteria}

$>$ All cases of Modified radical mastectomy operated from June 2018 to June 2019

\section{Exclusion Criteria}

$>$ Patients those who had undergone neoadjuvant Chemotherapy / Radiation.

$>$ Patients who had undergone previous breast surgery

All cases of metastatic Carcinoma breast .

\section{Core-needle biopsy}

A 14-gauge needle, such as the Tru-Cut needle. Automated devices also are available. Tissue specimens are placed in formalin and then processed to paraffin blocks. Although the falsenegative rate for core-needle biopsy specimens is low. Core-needle or open biopsy also permits the analysis of breast tissue architecture and allows the pathologist to determine whether invasive cancer is present.

The tissue for receptor study is sent at low temperature in ice flask. It is assessed by quantitative analysis (frozen $-70^{\circ}$ ) .If value is more than 10 units ( $\mathrm{f} / \mathrm{mols}$ ) per $\mathrm{n}$ gram of tissue is called estrogen receptor positive status. $60 \%$ of the post menopausal cases are usually estrogen receptor positive and premenopausal cases are $30 \%$ positive $\%$. The determination of estrogen and progesterone receptor status used to require biochemical evaluation of fresh tumor tissue. Now, estrogen and progesterone receptor status can be measured in archived tissue using immunohistochemical techniques.

\section{Hormonal therapy}

Based on the estrogen and progesterone receptor status of the tumor

\section{Pre menopausal}

- Tamoxifen -Antiestrogen

- Ovarian ablation by surgery

- Progesterone-Medroxyprogestrone

- Androgen-fluoxymestrone

\section{Post menopausal}

- Tamoxifen

- Aromatase inhibitor- Anestrazole, letrazole.

- Progesterone

- Androgen

\section{Chemotherapy}

- Advanced carcinoma as a palliative procedure

- Post operative period after simple mastectomy in stage III

- Inflammatory carcinoma

- In stage IV with secondary's in bone, lung, liver Premenopausal age group with poorly 
differentiated carcinoma Two types

- Neoadjuvant

- Adjuvant

\section{Drugs used in chemotherapy CMF regime}

- Cyclophosphamide

- Methotrexate

- 5 -Fluorouracil

CAF regime

- Cyclophosphamide

- Adriamycin

- 5 Fluorouracil

\section{Monoclonal Antibody \\ Trastuzumab}

It is a monoclonal antibody that blocks [human epidermal growth receptor] HER-2/neu receptor thereby preventing growth of cancer cells. It is a new drug now marketed as Herceptin .It is a cErbB2 (growth factor receptor) inhibitor it is a newer biological agent. It is effective in HER$2 /$ neu positive metastatic disease .

\section{Results and Discussion}

Among the 50 patients operated for carcinoma breast most of the patients in our study were post menopausal $(66 \%)$. Similar observations were noted in a study done by Azizun- Nisa et al ${ }^{18}$ where most of the patients were post menopausal (66\%). There was not much of a difference in ER,PR status in pre menopausal and post menopausal patients. This observation was similar to a study done by mohammad faheem et al. ${ }^{19}$ Most of the patients in our study presented with tumour size of T2 $(2 \mathrm{~cm}$ to $5 \mathrm{~cm})(68.2 \%)$. This observation was similar to a study done by Hussein et $\mathrm{al}^{20}$ where $69.8 \%$ of the patients were of tumour size T2. In our study the ER, PR negativity decreased with increase in size and HER 2 NEU over expression decreasing with increase in size. Similar observations were made by $\mathrm{Lu}$ et $\mathrm{al}^{23}$ which demonstrated a negative association between receptors and tumour size. This was in contrary to a study done by eisenberg et $\mathrm{al}^{16}$ where smaller tumours were ER positive.

Most of the patients in our study presented with a tumour grade $2(51.6 \%)$. Similar observations were made in a study done by Hussein et $\mathrm{al}^{20}$ where 55.2\% were grade 2 and Azizun- Nisa et al ${ }^{18}$ where $55.3 \%$ of patients were grade 2 . As the grade of the tumour increased the ER/PR negativity increased. Similar observations were made in studies done by Azizun- nisa et $\mathrm{al}^{18}$, Eisenberg et $\mathrm{al}^{16}$, Mohala et $\mathrm{al}^{15}$ and Almari et $\mathrm{al}^{17}$ where as the grade of the tumour increased the ER, PR negativity increased. In our study the most common pathological type of carcinoma was Ductal carcinoma NOS (80\%). Similar observation were made in a study done by Hussein et $\mathrm{al}^{20}$ where $90.5 \%$ of the patients were diagnosed to have Ductal carcinoma NOS. In our study most of the patients with pathological type of Ductal carcinoma NOS had ER/PR Negative. Medullary carcinoma had ER/PR and HER 2 NEU negative. Mucinous carcinoma had ER positive, PR positive and HER 2 NEU negative status.

In our study there was not much of a correlation between the nodal status and ER/ PR receptor status. This observation was similar to the study done by

Fatima et $\mathrm{al}^{22}$ and azizun- nisa et $\mathrm{al}^{18}$ where no significant correlation of receptor status and lymph node metastasis was seen. Most of our patients presented with absent lymphovascular invasion (64\%). There was no significant correlation noted between the receptor status and the lymphovascular invasion.

\section{Conclusion}

A total number of 50 patients with newly diagnosed infiltrating carcinoma of the breast were included in the study. Correlation of ER/PR and HER2NEU was done with other prognostic factors which were Menopausal status, Tumour size, Pathological type, Histological grading, Lymphovascular invasion and Nodal status.

Most of the patients in this study were post menopausal with tumour of stage T2. The commonest pathological type was Ductal 
Carcinoma NOS type. Majority of the patients had histological grade 2, and most number of patients presented with absent lymphovascular invasion $(64 \%)$. There was no significant correlation noted between the receptor status and the lymphovascular invasion.

The following results were observed:

As the grade of the tumour increased, ER/PR negativity increased with increase in Her 2 neu expression

There was no correlation found between ER/PR status and Menopausal status, tumour size, nodal status, lymphovascular invasion and pathological type.

There was no correlation found between Her 2 neu expression with tumour size and lymphovascular invasion.

The presence of positive estrogen, progesterone or HER2nue receptors will help people decide on the type of treatment. The women with estrogen, progesterone and HER2nue positive receptors can be started on hormone therapy which will be beneficial to them.

\section{References}

1. Birrell SN, Hall RE, Tilley WD. Role of the androgen receptor in human breast cancer. 1998;3:95-103.

2. Payne SJ, Bowen RL, Jones JL, Wells CA . Predictive markers in breast cancer the present. Histopathology.2008;52:82-90.

3. Ferlay J, Bray F, Pisani P. and Parkin DM . GEOBOCAN 2002. Cancer Incidence, Mortality and Prevalence Worldwide. IARC Cancer Base No. 5, version 2.0. IARC Press, Eyon, 2004.

4. Tewari M, Krishnamurthy A, Shukla HS . Predictive markers of response to neoadjuvant chemotherapy in breast cancer. Surg Oncol. 2008;7:301-311.

5. Mohammed HR, Eakatua DJ, Haus E, YasminehWJ .Estrogen and progesterone receptors in human breast cancer. Correlation with histological subtype and degree of differentiation in University of
Minnesota Cancer Cytopathology -CA: a Cancer Journal for Clinicians.2006; 58:1076-81.

6. Breasted JH: The Edwin Smith Surgical Papyrus. Chicago: University of Chicago Press,. Classics of Medicine Eibrary, vol. III. 1930;405 .

7. Celsus AC: De Medicina, Vol II. Eoeb Classical Eibrary Ed, Book V. Cambridge: Harvard University Press, 1935; p. 131.

8. Beenken SW5 et al: History of the therapy of breast cancer, in Bland and Copeland (eds): The Breast: Comprehensive Management of Benign and Malignant Disorders. Philadelphia: Saunders. 2004; p 5.

9. Moore $\mathrm{C}$ : On the influence of inadequate operations on the theory of cancer. R MedChirSoc. 1867; 1:244.

10. Halsted WS: I. The results of operations for the cure of cancer of the breast performed at the Johns Hopkins Hospital from June, 1889, to January, 1894. Ann Surg1894;20:497.

11. Richard Sainsbury. The Breast, Bailey and Love Short Practice of Surgery 25th edition 2008; 50:827-47.

12. Iglehart D J,Smith LB . The Breast ,Sabiston Text Book of Surgery 18th edition 2008; 7:861-96.

13. Bland I K,Beenken WS ,Copeland E M.The Breast Schwartz Text Principles of Surgery 9th edition 2008; 15:453-94.

14. Burstein HJ, Hams JR, Marrow M .Malignant Tumors of The Breast. Devita 8th edition 2008; 43.2: 1606-12.

15. Mohla S, Sampson C C, Enterline J P .Estrogen and Progestrone Receptors in Breast Cancer in Black Americans ,Correlation of Receptor Data with Tumor Differentiation, Cancer Journal 1982; 50: p552-59.

16. Eisenberg ALA, Koifman S..Hormone receptor Association with Prognostic Factor 
for Breast Cancer. Revista Brasileria de Cancerologia 2001 ;47:49-58.

17. Almasri $\mathrm{M} \quad \mathrm{N}$ and Hamad $\mathrm{M}$. Immunohistochemical evaluation of human epidermal growth factor receptor 2 and estrogen and progesterone receptors in breast carcinoma in Jordan Breast Cancer Research:2005;7: 598-604.

18. Azizun-Nisa1, Bhurgri Y, Raza F, Kayani N. Asian Comparison of ER, PR and HER2/neu (C-erb B 2) reactivity pattern with histologic grade, tumor size and lymph node status in breast cancer. Pac J. Can Prev 2008 Oct-Dec;9(4):553-6.

19. Faheem M1, Mahmood H, Khurram M, Qasim U, Irfan J. Estrogen receptor, progesterone receptor, and Her 2 Neu positivity and its association with tumour characteristics and menopausal status in a breast cancer cohort from northern Pakistan. Ecancermedicalsciene 2012;6: 283. doi: 10.3332 / ecancer.2012.283. Epub 2012 Dec 11

20. Hussein MR1, Abd-Elwahed SR, Abdulwahed AR.. Alterations of estrogen receptors, progesterone receptors and cerbB2 oncogene protein expression in ductal carcinomas of the breast. Cell Bio lint. 2008 Jun;32(6):698-707.

21. Naqvi SQH, Jamal Q, Mahmood RK, Zaidi $\mathrm{SMH}$, Abbas F. Significance of her 2 neu oncoprotein over expression on node positive invasive breast cancer. J. coll Physician Surg 2002.

22. Fatima S1, Faridi N, Gill S. Breast cancer: steroid receptors and other prognostic indicators. J. Coll. Physicians surg Pak 2005 Apr;15(4):230-3.

23. Lu X, Gu Y, Ding Y, Song W, Mao J, Tan J, Zhao H, Han X, Sun Y. Correlation of ER, PgR, HER-2/neu, p53, and VEGF with clinical characteristics and prognosis in Chinese women with invasive breast cancer. Breast Journal 008 May-Jun;14(3):308. 